\title{
Management of a doubly folded, partially inflated Melody valve after outer balloon rupture: a case report
}

\author{
Judith Schopen^^, Katarzyna Gendera, Peter Ewert, Harald Kaemmerer, Andreas Eicken \\ Department of Congenital Heart Disease and Pediatric Cardiology, German Heart Center Munich, Technical University of Munich, Munich, \\ Germany \\ Correspondence to: Judith Schopen. Lazarettstraße 36, 80636 Munich, Germany. Email: schopen@dhm.mhn.de.
}

\begin{abstract}
This is a report of a rare complication during implantation of a Melody valve in an adult patient in whom the valve failed to expand due to balloon rupture. An 18-year-old patient was admitted with an increased right ventricular pressure and severe pulmonary regurgitation for scheduled cardiac catheterization. Angiography revealed a proximal stenosis of the left pulmonary artery (LPA). First, a prestenting was performed. Three months later he came back for planned percutaneous pulmonary valve implantation (PPVI). Because of the proximity of the right coronary artery (RCA) to the right ventricular outflow tract (RVOT) and thus a relatively short landing zone, the Melody valve had been doubly folded. During the inflation of the outer balloon, it ruptured. At this point, the Melody valve was still fixed to the inner balloon. A second catheter was placed through the Melody valve and successful valve implantation was possible. This procedure was difficult because to push the catheter through the partly inflated Melody valve, the inner balloon had to be slowly and simultaneously deflated. The final angiograms and pressure measurements showed a good functional result and absent pulmonary regurgitation. Open heart surgery could be avoided after incomplete Melody valve dilatation using the contralateral pulmonary artery as a safe rail.
\end{abstract}

Keywords: Percutaneous pulmonary valve implantation (PPVI); doubly folded Melody valve; balloon rupture; case report

Submitted Aug 01, 2021. Accepted for publication Sep 27, 2021.

doi: $10.21037 / \mathrm{cdt}-21-487$

View this article at: https://dx.doi.org/10.21037/cdt-21-487

\section{Introduction}

Percutaneous pulmonary valve implantation (PPVI) has become the treatment of choice for right ventricular outflow tract (RVOT) regurgitation if technically feasible (1). Depending on the anatomy of the RVOT, prestenting may be required to create a safe landing zone for a percutaneous valve (2). Proximity of coronary arteries to the valve landing zone or complex RVOT anatomy may pose technical challenges. The following case of successful management of balloon rupture during a technically demanding PPVI with a Melody valve (Medtronic, Minneapolis, MN, USA) is presented in accordance with the CARE reporting checklist (available at https://dx.doi.org/10.21037/cdt-21-487).

\section{Case presentation}

An 18-year-old patient $(170 \mathrm{~cm}, 71.4 \mathrm{~kg})$ was admitted for planned PPVI. The patient was born with a ventricular septal defect, pulmonary valve stenosis, hypoplasia of the pulmonary valve annulus, and coarctation of the left pulmonary artery.

At the age of 6 weeks, surgery with a transannular RVOT patch, patch augmentation of the left pulmonary artery and ligation of the ductus arteriosus was performed.

Presently, 18 years later, an increased right ventricular pressure and severe pulmonary regurgitation was diagnosed by Doppler echocardiography and the patient was scheduled for cardiac catheterization with intended PPVI.

\footnotetext{
$\wedge$ ORCID: 0000-0002-9630-6092.
} 


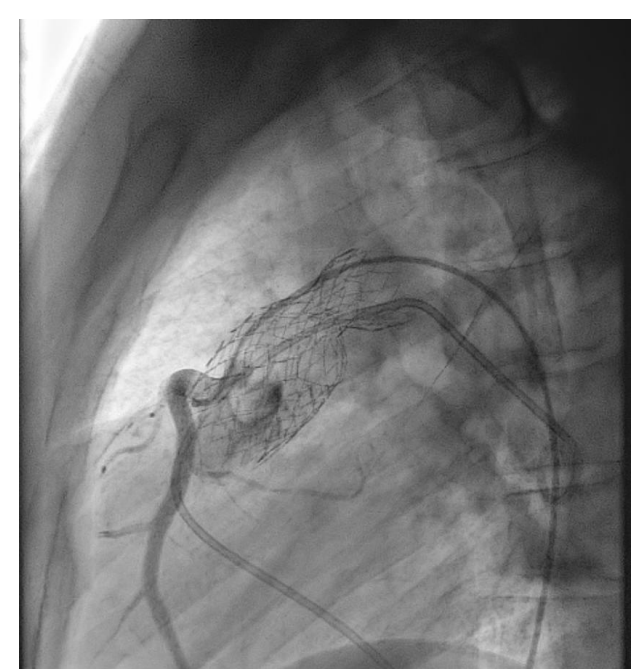

Figure 1 Selective coronarography shows the proximity of the RCA to the prestent.

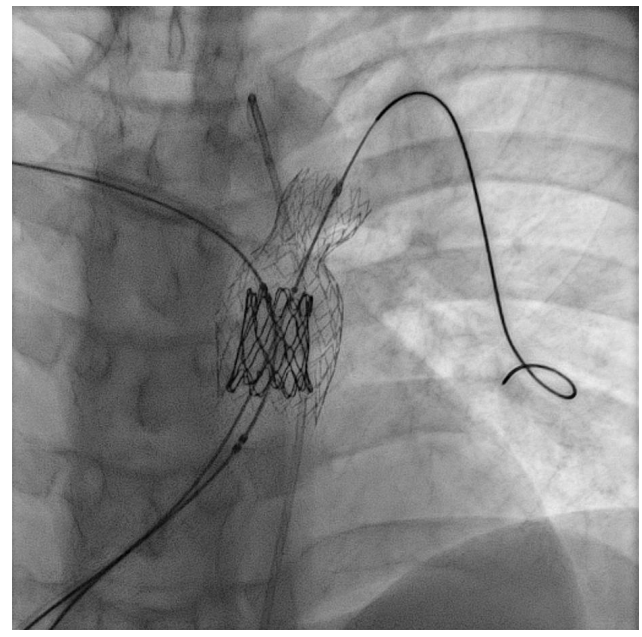

Figure 2 A second multipurpose catheter was placed through the Melody valve.

Systolic right ventricular pressure was $1 / 2$ of the systemic arterial pressure. The peak invasive pressure gradient across to the left pulmonary artery (LPA) was $35 \mathrm{mmHg}$, across to the right pulmonary artery (RPA) $15 \mathrm{mmHg}$. Angiography revealed a proximal stenosis of the LPA. A balloon test with a $28 \mathrm{~mm}$ VACS balloon (Osypka, Rheinfelden, Germany) and selective angiography of the right coronary artery (RCA) depicted the RCA close by but with sufficient distance to the RVOT. The diameter of the RVOT was $26-28 \mathrm{~mm}$. At first, prestenting was performed. A 57-mm Andra XXL Stent (AndraMed GmbH, Reutlingen, Germany), mounted on a $22-\mathrm{mm} \mathrm{BiB}$ (balloon-in-balloon) balloon (Numed, Hopkinton, NY, USA), was delivered to relieve the LPA stenosis. Since the central pulmonary artery was large, the proximal end of the stent was dilated with a $28-\mathrm{mm}$ VACS balloon. The orifice of the RPA was reopened with an 8-mm Powerflex- (Johnson \& Johnson, Miami, FL, USA) and later with a 16-mm Atlas balloon (BARD Peripheral Vascular Inc., Tempe, AZ, USA). Selective coronary angiography showed close proximity of the RCA to the anticipated valve landing zone (Figure 1).

Three months later a minimal stent diameter of $21 \mathrm{~mm}$ was assessed. In view of the short safe valve landing zone measured $16 \mathrm{~mm}$, it was decided to implant a doubly folded Melody valve on a $22-\mathrm{mm} \mathrm{BiB}$ balloon. A superstiff 0.035 guide wire was positioned through the cracked Andra stent into the right pulmonary artery. During valve delivery, the outer balloon ruptured at the RPA origin and the partially inflated Melody valve was still fixed on the inner balloon at this time. The left femoral vein was cannulated and a $5 \mathrm{~F}$ Multipurpose catheter was placed through the Melody valve (Figure 2).

This procedure was difficult because to push the catheter through the partly inflated Melody valve, the inner balloon had to be slowly and simultaneously deflated. Then, a $22 \times 20 \mathrm{~mm}$ Atlas Gold balloon was advanced into the LPA on a second superstiff guidewire and fully inflated, thereby safely deploying the Melody valve. Both the Atlas balloon and the delivery system could then be removed. The final angiograms and pressure measurements showed a good functional result with a residual PA-RV gradient $<10 \mathrm{mmHg}$ and absent pulmonary regurgitation (Figure 3).

All procedures performed in studies involving human participants were in accordance with the ethical standards of the institutional and/or national research committee(s) and with the Helsinki Declaration (as revised in 2013). Written informed consent was obtained from the patient for publication of this case report and accompanying images. A copy of the written consent is available for review by the editorial office of this journal.

\section{Discussion}

We present the case of a young adult with a "native" RVOT, LPA stenosis, severe pulmonary regurgitation and close proximity of the RCA to the RVOT, so the valve landing zone was short. During the inflation of a doubly folded Melody valve on a $22-\mathrm{mm}$ delivery system with wire position through the cracked Andra stent in the right 


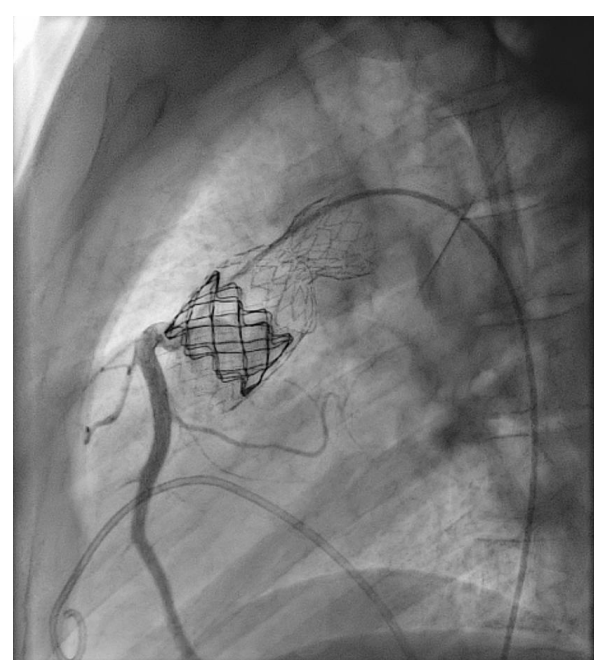

Figure 3 The melody valve was in a good position. Selective coronarangiography showed good perfusion of the right coronary artery.

pulmonary artery, the outer balloon ruptured at the RPA origin, and the partially inflated Melody valve became fixed on the inner balloon. Therefore, a second catheter was placed through the Melody valve, and safe valve inflation was possible with wire position in the left pulmonary artery.

PPVI is a safe and effective treatment for RVOT regurgitation in patients with valved conduits (3) and in selected patients with a "native" RVOT as well (4). In some patients with "native" RVOTs, PPVI can even be performed without prestenting using the Sapien valve (5).

The complications rate after PPVI has been shown to be low (6) and the long-term outcome is excellent if a low residual RVOT gradient $(<15 \mathrm{mmHg})$ can be achieved. The results of PPVI with the Melody valve are similar to those after surgical pulmonary valve replacement, but with less distress for the patients (7).

A case on a dislodged Melody valve during difficult valve delivery, with catheter interventional retrieval of the valve and subsequent successful PPVI was published by Gendera et al. in 2018 (8). In the present case reopening of the Andra stent to the right pulmonary artery must have resulted in stent struts protruding into the vessel lumen. Valve delivery with RPA wire position through the reopened stent caused rupture of the outer delivery balloon.

Obviously, a wire position through a "cracked" bare metal stent is not advisable during PPVI. The left PA should have been chosen for valve deployment.

A similar situation in which a balloon ruptured during prestenting has been described. In this case, the problem was solved by using a double-balloon technique (9).

Folding a Melody valve from both ends significantly shortens the Melody valve, enabling PPVI in patients with a short "landing zone", as was present in our patient (10).

In conclusion, open heart surgery could be avoided after incomplete Melody valve dilatation due to rupture of the outer delivery balloon by high pressure balloon dilatation using the contralateral pulmonary artery as a safe rail.

\section{Acknowledgments}

Funding: None.

\section{Footnote}

Provenance and Peer Review: This article was commissioned by the editorial office, Cardiovascular Diagnosis and Therapy for the series "Current Management Aspects in Adult Congenital Heart Disease (ACHD): Part IV". The article has undergone external peer review.

Reporting Checklist: The authors have completed the CARE reporting checklist. Available at https://dx.doi. org/10.21037/cdt-21-487

Peer Review File: Available at https://dx.doi.org/10.21037/ cdt-21-487

Conflicts of Interest: All authors have completed the ICMJE uniform disclosure form (available at https:// dx.doi.org/10.21037/cdt-21-487). The series "Current Management Aspects in Adult Congenital Heart Disease (ACHD): Part IV" was commissioned by the editorial office without any funding or sponsorship. HK serves as an unpaid editorial board member of Cardiovascular Diagnosis and Therapy from February 2018 to January 2022 and served as the unpaid Guest Editor of the series. HK has received honoraria for lectures and/or consultancy from Actelion, Bristol Myers Squibb and Janssen. PE and AE are proctors for the Melody Valve and the Sapien Pulmonic valve. The authors have no other conflicts of interest to declare.

Ethical Statement: The authors are accountable for all aspects of the work in ensuring that questions related to the accuracy or integrity of any part of the work are appropriately investigated and resolved. All procedures performed in studies involving human participants were in 
accordance with the ethical standards of the institutional and/or national research committee(s) and with the Helsinki Declaration (as revised in 2013). Written informed consent was obtained from the patient for publication of this case report and accompanying images. A copy of the written consent is available for review by the editorial office of this journal.

Open Access Statement: This is an Open Access article distributed in accordance with the Creative Commons Attribution-NonCommercial-NoDerivs 4.0 International License (CC BY-NC-ND 4.0), which permits the noncommercial replication and distribution of the article with the strict proviso that no changes or edits are made and the original work is properly cited (including links to both the formal publication through the relevant DOI and the license). See: https://creativecommons.org/licenses/by-nc-nd/4.0/.

\section{References}

1. Georgiev S, Ewert P, Tanase D, et al. A Low Residual Pressure Gradient Yields Excellent Long-Term Outcome After Percutaneous Pulmonary Valve Implantation. JACC Cardiovasc Interv 2019;12:1594-603.

2. Georgiev S, Tanase D, Ewert P, et al. Percutaneous pulmonary valve implantation in patients with dysfunction of a "native" right ventricular outflow tract - Mid-term results. Int J Cardiol 2018;258:31-5.

3. Khambadkone S, Coats L, Taylor A, et al. Percutaneous

Cite this article as: Schopen J, Gendera K, Ewert P, Kaemmerer H, Eicken A. Management of a doubly folded, partially inflated Melody valve after outer balloon rupture: a case report. Cardiovasc Diagn Ther 2021;11(6):1432-1435. doi: $10.21037 / \mathrm{cdt}-21-487$ pulmonary valve implantation in humans: results in 59 consecutive patients. Circulation 2005;112:1189-97.

4. Demkow M, Rużyłło W, Biernacka EK, et al. Percutaneous Edwards SAPIEN $\left({ }^{\mathrm{TM}}\right)$ valve implantation for significant pulmonary regurgitation after previous surgical repair with a right ventricular outflow patch. Catheter Cardiovasc Interv 2014;83:474-81.

5. Tanase D, Georgiev S, Eicken A, et al. The Sapien valve provides enough grip to be implanted in pulmonary position without a pre-stent. Cardiovasc Diagn Ther 2019;9:S264-8.

6. Eicken A, Ewert P, Hager A, et al. Percutaneous pulmonary valve implantation: two-centre experience with more than 100 patients. Eur Heart J 2011;32:1260-5.

7. Georgiev S, Ewert P, Eicken A, et al. Munich Comparative Study: Prospective Long-Term Outcome of the Transcatheter Melody Valve Versus Surgical Pulmonary Bioprosthesis With Up to 12 Years of Follow-Up. Circ Cardiovasc Interv 2020;13:e008963.

8. Gendera K, Ewert P, Eicken A. Percutaneous retrieval of a partially flared Melody valve. Cardiol Young 2018;28:753-5.

9. Faccini A, Chessa M, Aljoufan M. Management of balloon rupture during a percutaneous pulmonary valve implantation procedure. Cardiol Young 2018;28:1168-70.

10. Jalal Z, Valdeolmillos E, Malekzadeh-Milani S, et al. MidTerm Outcomes Following Percutaneous Pulmonary Valve Implantation Using the "Folded Melody Valve" Technique. Circ Cardiovasc Interv 2021;14:e009707. 